\title{
ACESSO ÀS INSTITUIÇÕES FEDERAIS DE ENSINO SUPERIOR BRASILEIRAS APÓS A LEI DE COTAS
}

\author{
Luciana Alaíde Alves Santana (UFRB/DIVERSIFICA)* \\ https://orcid.org/0000-0002-1103-1158 \\ Everson Meireles (UFRB/DIVERSIFICA)** \\ https://orcid.org/0000-0002-1715-006X \\ José Jorge de Carvalho (UnB)*** \\ https://orcid.org/0000-0003-3415-3534
}

\section{RESUMO}

Buscou-se avaliar, no âmbito das Instituições Federais de Ensino Superior (IFES) brasileiras, como se deu a consecução das metas estabelecidas na Lei no 12.711 . Foram analisados microdados do Censo da Educação Superior no período de 2013-2016. A partir de análises descritivas, foi possível observar marcante mudança no perfil dos ingressantes no período estudado. Em 2016, 38,2\% das matrículas em vagas novas nas IFES eram de ingressantes pelo Programa de Reserva de Vagas (PRV). As IFES localizadas no Nordeste do país foram as que promoveram maior acesso via cotas; as do Sudeste, menor. Os critérios de inclusão que viabilizaram maior número de ingressos via PRV foram escola pública, étnico/racial e renda, respectivamente. Foi observado ampliação do acesso em todos os turnos e áreas de conhecimento. Concluiu-se que o percentual de ingresso via PRV se aproximou da meta de $50 \%$ apregoada pela Lei, tendo sido promovida maior diversidade no campus.

Palavras-chave: Ensino superior. Políticas afirmativas. Lei de cotas.

\section{ABSTRACT}

\section{ACCESS TO BRAZILIAN FEDERAL INSTITUTIONS OF HIGHER EDUCATION AFTER THE QUOTAS LAW}

It was sought to evaluate, within the framework of the Federal Institutions of Higher Education in Brazil, how the goals established in Law 12.711 were achieved. Microdata of the Higher Education Census was analyzed in the period 2013-2016. Based on descriptive analysis, it was possible to observe a marked

\footnotetext{
Doutora em Ciências da Educação pelo Instituto de Educação da Universidade do Minho, Portugal. Professora da Universidade Federal do Recôncavo da Bahia/Observatório da Inclusão e Diversidade na Educação Brasileira (UFRB/DIVERSIFICA), Campus de Santo Antônio de Jesus, Bahia. E-mail: lualaide@ufrb.edu.br

** Doutor em Psicologia pela Universidade São Francisco (USF). Professor da Universidade Federal do Recôncavo da Bahia/ Observatório da Inclusão e Diversidade na Educação Brasileira (UFRB/DIVERSIFICA), Campus de Santo Antônio de Jesus, Bahia. E-mail: emeireles@ufrb.edu.br

*** PhD em Antropologia Social pela The Queen's University of Belfast. Professor da Universidade de Brasília (UnB). Bolsista de Produtividade em Pesquisa do CNPq - Nível 1A. Coordenador do Instituto Nacional de Ciência e Tecnologia e Inclusão no Ensino Superior e na Pesquisa (INCT), do Ministério de Ciência e Tecnologia e do CNPq. E-mail: jorgedc@terra.com.br
} 
change in the profile of the participants in the studied period. In 2016,38.2\% of enrollments in new places at IFES were those enrolled by the Vacancy Reserve Program (VRP). The IFES located in the Northeast of the country were the ones that promoted greater access through quotas; those of the Southeast, minor. The inclusion criteria that enabled the highest number of tickets via VRP were public school, ethnic / racial and income, respectively. Access was observed in all shifts and areas of knowledge. It was concluded that the percentage of admission via VRP approached the goal of $50 \%$ proclaimed by the Law, having promoted greater diversity on campus.

Keywords: Higher education. Affirmative policies. Quotas law.

\section{RESUMEN}

\section{ACCESO A LAS INSTITUCIONES FEDERALES DE ENSEÑANZA SUPERIOR BRASILEÑAS DESPUÉS DE LA LEY DE CUOTAS}

Se buscó evaluar, en el ámbito de las Instituciones Federales de Enseñanza Superior (IFES) brasileñas, cómo se dio la consecución de las metas establecidas en la Ley 12.711. Se analizaron microdatos del Censo de Educación Superior en el período 2013-2016. A partir de análisis descriptivos fue posible observar fuete cambio en el perfil de los ingresantes en el período estudiado. En 2016, el 38,2\% de las matrículas en vacantes nuevas en las IFES eran de ingreso por el Programa de Reserva de Vacantes (PRV). Las IFES localizadas en el Nordeste del país fueron las que promovieron mayor acceso vía cuotas; las del Sudeste, menor. Los criterios de inclusión que viabilizaron mayor número de ingresos vía PRV fueron la escuela pública, étnica / racial y renta, respectivamente. Se observó ampliación del acceso en todos los turnos y áreas de conocimiento. Se concluyó que el porcentaje de ingreso vía PRV se aproximó a la meta del 50\% pregonada por la Ley, habiendo sido promovida mayor diversidad en el campus.

Palabras clave: Enseñanza superior. Políticas afirmativas. Ley de cuotas.

\section{Introdução $0^{1}$}

Na rede federal de ensino superior brasileira, no período entre 2004-2014, uma característica marcante foi a expansão do número de matrículas. De acordo com dados do Instituto Nacional de Estudos e Pesquisas Educacionais Anísio Teixeira (Inep) no ano de 2004 havia, no Brasil, 4.163.733 estudantes matriculados na rede de educação superior (INSTITUTO NA-

1 Este estudo utilizou dados secundários, obtidos a partir de microdados públicos que reúnem informações sobre o Censo da Educação Superior, disponibilizados pelo Instituto Nacional de Estudos e Pesquisas Educacionais Anísio Teixeira (INEP). Os dados foram analisados, apresentados e discutidos em observância aos princípios éticos envolvidos neste tipo de pesquisa.
CIONAL DE ESTUDOS E PESQUISAS EDUCACIONAIS ANÍSIO TEIXEIRA, 2007). No relatório do primeiro ano do Programa de Apoio a Planos de Reestruturação e Expansão das Universidades Federais - REUNI (BRASIL, 2007a) elaborado pelo Ministério da Educação (BRASIL, 2009), há registro do aumento de 14.826 novas vagas e incremento de 9,7\% no número de cursos. Em outro importante documento, a Associação dos Dirigentes das Instituições Federais de Ensino Superior (Andifes) produziu um relatório sobre REUNI no período 2007-2010, tendo registrado que as universidades federais aumentaram em $49 \%$ a oferta de vagas nos cursos de graduação, 
com 65.306 novas vagas (ASSOCIAÇÃ̃O DOS DIRIGENTES DAS INSTITUIÇÕES FEDERAIS DE ENSINO SUPERIOR, 2019).

No ano de 2016 foram registradas 8.048 .701 de matrículas na rede de ensino superior brasileira, o que significa dizer que no período de dez anos houve um incremento de $62,8 \%$. Deste total, $6.058 .623(75,3 \%)$ estudantes estavam matriculados em instituições privadas e $1.990 .078(24,7 \%)$ em instituições públicas. Na rede pública, especificamente, as Instituições Federais detinham 1.249.324 (62,8\% das matrículas), dentre as quais $86,7 \%$ estavam em Universidades e 13,2\% em Institutos Federais (INSTITUTO NACIONAL DE ESTUDOS E PESQUISAS EDUCACIONAIS ANÍSIO TEIXEIRA, 2017).

Nesse cenário de ampliação do acesso, foi evidente a diversificação territorial da rede federal, com mudanças provenientes da expansão e criação de campus universitários no interior do país. De 2003 a 2014, houve um salto no número de universidades federais de 45 para 63, o que representou uma ampliação de $40 \%$ nesse total. 0 número de campi universitários passou de 148 para 321 , crescimento de $117 \%$. As discrepâncias regionais na distribuição de instituições federais de ensino superior ainda permaneceram, todavia, registra-se que nas regiões menos favorecidas (Norte e Nordeste) e nas cidades do interior houve ampliação do número de universidades.

Tal diversificação também foi observada quanto ao perfil autodeclarado de raça/cor do alunado. Estudo pregresso realizado por Ristoff (2014) constatou que havia predomínio de pessoas autodeclaradas brancas em todos os cursos de graduação, sobretudo naqueles de maior prestígio social (ex.: Medicina, Medicina Veterinária, Direito, Odontologia etc.). No ano de 2010 o campus brasileiro era cerca de $20 \%$ mais branco que a população brasileira, embora aponte tendência de mudança da super-representação branca nos cursos de graduação ofertados no país nos anos seguintes. Quanto aos estudantes autodeclarados pretos, o estudo apontou uma representação próxima ou superior à sociedade brasileira, em cursos de menor demanda, e percentuais inferiores para os cursos mais competitivos. A maior discrepância em relação à cor no campus e na sociedade foi registrada para os autodeclarados pardos; em todos os cursos, os pardos estavam sub-representados.

Outros estudos sobre o perfil do estudante têm sido realizados pela Associação de Dirigentes de Instituições Federais de Ensino Superior/Fórum Nacional de Pró-Reitores de Assuntos Comunitários e Estudantis (Andifes/ Fonaprace). No ano de 2019 foi lançado o Relatório "Perfil Socioeconômico e Cultural dos Estudantes de Graduação das Universidades Federais Brasileiras", que traz informações sobre a quinta edição da pesquisa amostral, iniciada no ano de 1996. Neste documento é notável a mudança no perfil dos estudantes das IFES: os autodeclarados brancos representavam 59,4\% dos estudantes em 2003, 45,7\% em 2014 e em 2018 43,3\%; pardos, de 28\% em 2003 para 37,75\% em 2014, em 2018, 39,2\%; pretos, de 5,9\% em 2003, para 9,8\% em 2014 e $12 \%$ em 2018 ; indígenas, de $0,19 \%$ no ano de 2003 para $0,40 \%$ no ano de 2014 e $0,90 \%$ em 2018. 0 Relatório também mostrou um incremento no percentual de ingressantes provenientes do ensino médio realizado exclusivamente em escolas públicas, chegando a $64,6 \%$ dentre os que ingressaram no período entre 2013 a 2015 . Na amostra da pesquisa realizada em 2018, o percentual dos estudantes que cursaram o ensino médio exclusivamente em escolas públicas foi de 64,7\%. Em relação à renda familiar bruta, no ano de 2010 era de $26,5 \%$ o percentual daqueles estudantes com renda de até dois salários mínimos, tendo alcançado a marca de $36,7 \%$ no ano de 2014 e 35,9\% no ano de 2018 (ASSOCIAÇÃO DOS DIRIGENTES DAS INSTITUIÇÕES FEDERAIS DE ENSINO SUPERIOR, 2019).

Neste cenário de democratização do campus universitário da rede federal é oportuno registrar a importância de ações afirmativas 
de cunho étnico-racial e/ou social, com foco na ampliação do acesso de grupos historicamente discriminados pela exclusão socioeconômica e/ou cultural e alijados do ensino superior. Não só a rede federal, mas todas as categorias administrativas públicas foram sensibilizadas pelo movimento da sociedade civil, em especial o Movimento Negro (CARVALHO, 2016; SANTOS, 2012) em prol da implantação de reserva de vagas. Em análise sobre como foram concebidas e implementadas as ações afirmativas no seio das universidades públicas brasileiras, Carvalho (2016) apontou que existiam mais diferenças que similaridades no modo como tais IES levaram a cabo seus sistemas de reserva de vagas, com evidente polarização entre as chamadas cotas sociais e as cotas raciais.

O marco temporal da implantação de reserva de vagas para grupos discriminados foi o ano de 2001, quando o Estado do Rio de Janeiro promulgou a Lei Estadual n. 3.708, de 9 de novembro de 2001, que previa reserva de até $40 \%$ das vagas ofertadas pela Universidade do Estado do Rio de Janeiro - UERJ e pela Universidade Estadual do Norte Fluminense - UENF, para indivíduos autodeclarados pretos ou pardos. Estas universidades, ao implementarem esta Lei, definiram os seguintes critérios de reserva de vagas: $45 \%$ para estudantes de baixa renda (até $\mathrm{R} \$ 960,00$ per capta), sendo: $20 \%$ para candidatos de escolas públicas; $20 \%$ para negros e indígenas e $5 \%$ para minorias, definidas como pessoas com deficiências e/ou filhos de policiais, bombeiros e agentes penitenciários, mortos ou incapacitados em serviço (CARVALHO, 2016; SANTOS, 2012).

Na Bahia destaca-se o protagonismo da Universidade Estadual da Bahia (UNEB), que em 2002 implantou reserva de vagas com os seguintes critérios: $45 \%$ para candidatos de escolas públicas com renda familiar até quatro salários mínimos, sendo $40 \%$ para negros e $5 \%$ para indígenas. No mesmo ano, na rede federal de ensino superior, a Universidade Fe- deral do Mato Grosso do Sul (UFMS) reservou 120 vagas no curso de Licenciatura específica para indígenas. No ano seguinte, a Universidade de Brasília - UnB instituiu seu Programa de Reserva de Vagas (PRV) com de 20\% para negros, 10 vagas para indígenas e sistema de bonificação de $20 \%$ na nota de candidatos de escolas públicas nos campi de Ceilândia, Gama e Planaltina (CARVALHO, 2016; GUARNIERI; MELO-SILVA, 2017; HERINGER; FERREIRA, 2009; SANTOS, 2012).

A partir do ano de 2004 as instituições federais aplicaram com mais robustez as ações afirmativas, permitindo a reserva de vagas para acesso à universidade por meio de Resoluções próprias dos seus Conselhos Universitários. 0 princípio dessa expansão geométrica e surpreendente, obra quiçá do inconsciente político dos segmentos acadêmicos, foi o da diferenciação progressiva: cada IFES propôs um modelo próprio de ação afirmativa, com alguma variante em relação aos modelos anteriores (CARVALHO, 2016).

No âmbito da rede federal de ensino superior, como parte da agenda do governo, em 2007, o Ministério da Educação (MEC) lançou o Plano de Desenvolvimento da Educação (PDE). Naquele momento, referindo-se ao PDE, o MEC considerou o Plano em tela como um conjunto de programas que visavam dar consequência às metas quantitativas estabelecidas pelo Plano Nacional de Educação (PNE) - 2001-2011 (BRASIL, 2007b). O PDE adotou um conjunto de princípios, dente eles:

[...] a promoção de inclusão social pela educação, minorando nosso histórico de desperdício de talentos, considerando que dispomos comprovadamente de significativo contingente de jovens competentes e criativos que têm sido sistematicamente excluídos por um filtro de natureza econômica. (BRASIL, 2007b, p. 27).

Posteriormente ocorreu a ampliação definitiva da política a partir da promulgação da Lei $\mathrm{n}$ - 12.711, conhecida como a Lei de Cotas (BRASIL, 2012). A aprovação desta Lei no Congresso Nacional ocorreu após julgamento, pelo 
Supremo Tribunal Federal (STF), da ação de inconstitucionalidade impetrada pelo Partido Democrata (DEM), contra o sistema de cotas para negros na UnB, quando o STF decidiu pela constitucionalidade deste sistema de reserva de vagas.

A Figura 1 ilustra os critérios de reserva de vagas nas IFES definidos pela Lei 12.711.

Figura 1 - Esquema explicativo da Lei de Cotas

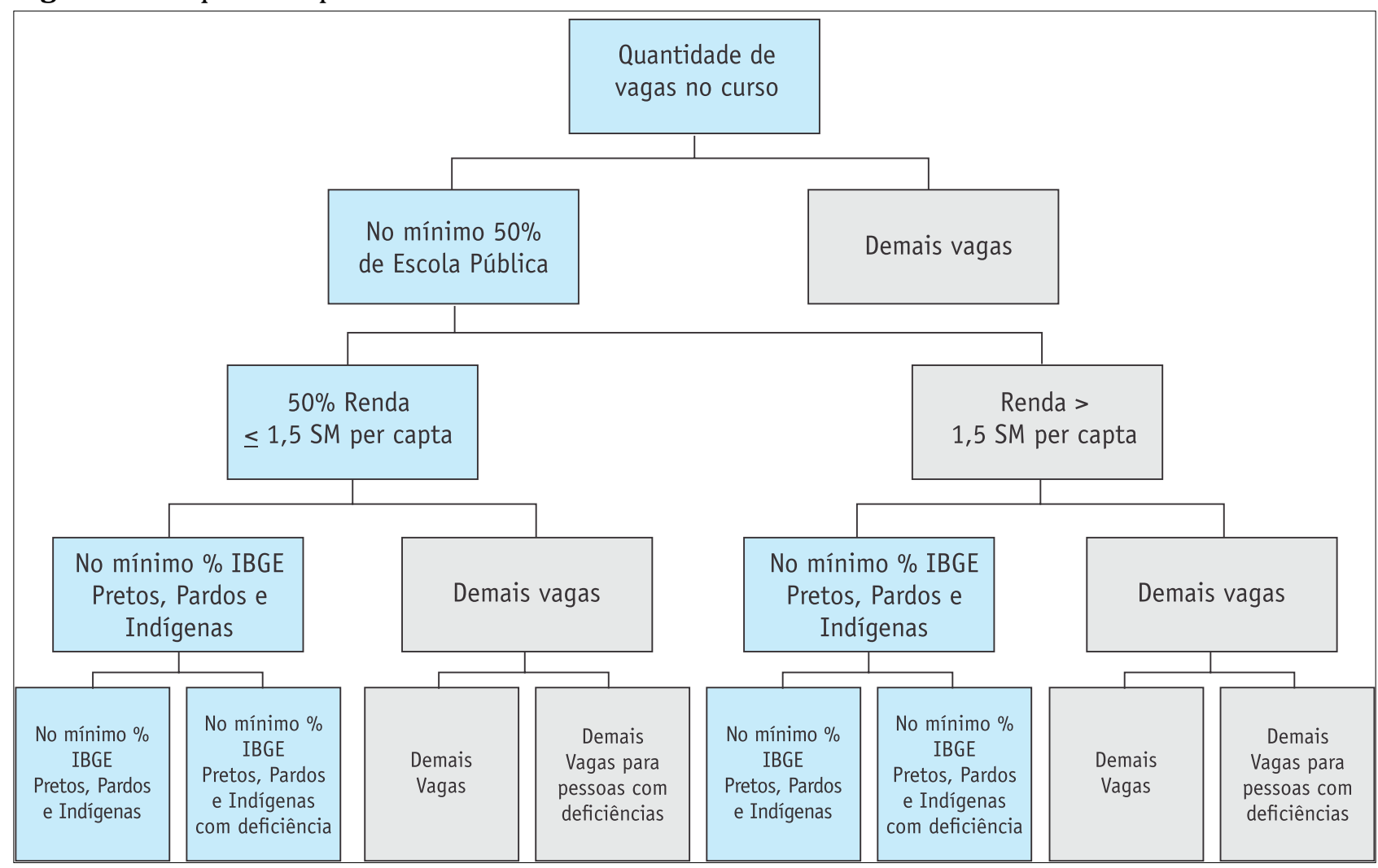

Fonte: Adaptado pelos autores deste artigo de Ministério da Educação (2012).

Conforme esboçado na Figura 1, a Lei de Cotas definiu, no seu artigo $1^{\circ}$, a reserva de $50 \%$ das vagas em processos seletivos (por turno e cursos) ofertados em institutos e universidades federais, para ingresso de estudantes com histórico de escolarização integral em escola pública. Em seguida, em Parágrafo Único, a Lei definiu que $50 \%$ destas vagas deveriam ser reservadas aos estudantes oriundos de famílias com renda igual ou inferior a 1,5 salários-mínimos per capita (BRASIL, 2012).

Os critérios de raça/cor foram definidos pelo seu artigo $3^{\circ}$, que estabeleceu como regra a proporção no mínimo igual à de pretos, pardos e indígenas na população da unidade da Federação onde está instalada a instituição, segundo o último censo do Instituto Brasileiro de Geografia e Estatística (IBGE). 0 referido artigo foi alterado mais recentemente, em redação dada pela Lei no $13.409,{ }^{2}$ de 2016 (BRASIL, 2016), passando a assegurar também a inclusão de pessoas com deficiência. A Lei determina ainda, em seu Art. 8o, que as instituições reservem, no mínimo $25 \%$ a cada ano da reserva de vagas prevista, com prazo máximo de 4 (quatro) anos, a partir da data de sua publicação, para cumprir integralmente o disposto na Lei (BRASIL, 2012).

A temática da reserva de vagas em Instituições Federais de Ensino Superior (IFES) tem motivado um amplo debate na sociedade, repercutindo também no meio acadêmico. Em uma análise crítica acerca da Lei de Cotas, Car-

2 A Lei 13.409 de 2016 alterou a redação do Artigo 3ํ da Lei 12.711 de 2012, incluindo a autodeclaração de pessoas com deficiência. 
valho (2016) assinalou que esta propõe simultaneamente a justiça social, racial, étnica, todas submetidas à precedência da justiça republicana, esta última entendida como a garantia de acesso livre e irrestrito à escola pública para todos os cidadãos. 0 referido autor argumenta que esta tratativa da Lei, de forma unidimensional e condicionada, faz com que a justiça republicana se sobreponha às demais, de forma de inviabilizar a plena igualdade social, étnica e racial. Recorrendo ao vocabulário marxiano e espinosano, Carvalho (2016, p. 108) afirma que "o sujeito subsumido à outra categoria, que se impõe como mais abrangente e prioritária que a dele mesmo, diminui inevitavelmente a sua potência; logo, diminui seus recursos e sua capacidade de emancipar-se".

Guarnieri e Melo-Silva (2017), ao analisarem o estado da arte da produção científica nacional sobre cotas em universidades ao longo de uma década (2003-2013), recuperaram 109 artigos publicados em 30 diferentes periódicos. Ao avaliarem as tendências temáticas nesses estudos, as autoras identificaram que cinco grandes categorias emergem das publicações: embates teóricos e legais sobre as cotas $(70,6 \%)$; impactos das cotas nas universidades $(70,6 \%)$; perspectivas diversas sobre as cotas $(36,7 \%)$; critérios de inclusão $(17,4 \%)$; comparação entre países $(14,7 \%)$. Identificaram ainda que, num primeiro período (2003 a 2008; 48 artigos), os estudos enfatizavam basicamente questões relativas à constitucionalidade das cotas e, num segundo período (2009 a 2013; 61 artigos), focavam mais nos efeitos das experiências com a temática das cotas nas universidades e seus impactos na sociedade brasileira.

Na linha dos estudos que buscam avaliar os efeitos da Lei de Cotas nos perfis de ingresso, o presente artigo teve como interesse precípuo avaliar, no âmbito das IFES, como se deu a implantação da Lei no $12.711 / 2012$. Buscouse identificar se o campus da rede federal de ensino tornou-se mais diverso e democrático, por ter permitindo o ingresso de pessoas de variados grupos, particularmente os oriundos de escola pública, de famílias de baixa renda, bem como da população negra (preta e parda) e indígenas, os quais representam o grupo-alvo da política afirmativa.

\section{Método}

Trata-se de um estudo que se utilizou de dados secundários, obtidos a partir de microdados públicos que reúnem informações sobre o Censo da Educação Superior, disponibilizados pelo Instituto Nacional de Estudos e Pesquisas Educacionais Anísio Teixeira (INEP). A coleta de informações censitárias realizadas pelo INEP ocorre junto às IES que ofertam cursos de graduação e sequenciais de formação específica. Os dados obtidos são provenientes de questionários preenchidos pelos Pesquisadores Institucionais (PIs) de cada instituição, bem como por meio da importação de dados do Sistema e-MEC. Durante o período de preenchimento do questionário, os PIs podem fazer, a qualquer momento, alterações ou inclusões necessárias nos dados das respectivas instituições. Após esse período, o Inep verifica a consistência das informações coletadas. 0 sistema do Censo é então reaberto para conferência e validação dos dados pelas IES. Deste modo, trata-se de uma base produzida pelas instituições de ensino e submetida a um sistema de validação concebido pelo Inep.

No presente estudo, os dados foram extraídos da "base aluno", tendo sido adotado como recorte temporal o período de 2013-2016 e filtro para as Instituições Federais de Ensino Superior (IFES). A definição deste período de estudo se deu em razão da data da promulgação da Lei no 12.711, em agosto de 2012, e sua efetiva implantação a partir do ano de 2013. $\mathrm{Na}$ base aluno foram analisados os dados de ingresso em vagas novas de estudantes em 107 IFES $^{3}$ distribuídas nas cinco regiões do país, sendo: 63 Universidades Federais, 38 Institutos, 4 Faculdades e 2 Centros.

\footnotetext{
3 No ano de 2013 há dados sobre 62 Universidades Federais; para 2014-2016 estão agregados dados de 63 Universidades.
} 
Partiu-se do entendimento de que seria mais informativo trabalhar com dados reais de ingresso em vagas novas nas IFES em vez de apenas os percentuais de oferta destas nas modalidades, especialmente pelo programa de reserva de vagas. As informações mineradas foram as seguintes: número de ingressantes nas IFES, considerando o ingresso em vagas novas por modalidade de ingresso (ampla concorrência e programa de reserva de vagas), turno do curso (matutino, vespertino, integral ou noturno) e Grande Área de Conhecimento do curso de graduação do estudante, segundo classificação adotada pela Organização para a Cooperação e Desenvolvimento Econômico (OCDE) (GABINETE DE ESTATÍSTICAS DA UNIÃO EUROPEIA; ORGANIZAÇÃO DAS NAÇÕES UNIDAS PARA A EDUCAÇÃO, A CIÊNCIA E A CULTURA; ORGANIZAÇÃO PARA A COOPERAÇÃO E DESENVOLVIMENTO ECONÔMICO, 2000). Os dados foram exportados para o software estatístico IBM SPSS Statistics 23, a partir do qual puderam ser obtidas informações sobre o fenômeno estudado por meio de recursos da estatística descritiva.

\section{Resultados e Discussão}

Ao considerar o total geral de ingresso em vagas novas oferecidas pelas Instituições Federais de Ensino Superior (IFES) brasileiras no período de 2013 a 2016, observou-se incremento de 5,4\% no número de ingressantes, representando 15.864 matrículas a mais no país. Se analisado por regiões (ver Tabela $1)$, os percentuais de incremento no ingresso foram os seguintes: $\mathrm{Sul}(12,6 \%)$; Centro-Oeste $(6,8 \%)$; Sudeste $(4,7 \%)$; Nordeste $(2,4 \%)$ e Norte $(2,2 \%)$. No ano de 2016 , as regiões Sudeste $(31,2 \%)$ e Nordeste $(29,9 \%)$ detinham $61,1 \%$ das matrículas de ingressantes em vagas novas na IFES brasileiras.

Tabela 1 - Evolução do quantitativo de ingressantes nas IFES por Região, considerando o total geral e diferentes modalidades de ingresso nos anos de 2013 a 2016

\begin{tabular}{|c|c|c|c|c|c|c|c|c|c|c|c|c|}
\hline \multirow{3}{*}{ Regiões } & \multirow{2}{*}{\multicolumn{4}{|c|}{$\begin{array}{c}\text { Total geral de ingressos } \\
\text { nas IFES }\end{array}$}} & \multicolumn{8}{|c|}{ Modalidades de ingresso } \\
\hline & & & & & \multicolumn{4}{|c|}{ Ampla Concorrência (AC) } & \multicolumn{4}{|c|}{ Programa de Reserva de Vagas (PRV) } \\
\hline & 2013 & 2014 & 2015 & 2016 & 2013 & 2014 & 2015 & 2016 & 2013 & 2014 & 2015 & 2016 \\
\hline Nordeste & 85.431 & 94.062 & 85.617 & 87.521 & 70.543 & 69.301 & 56.422 & 52.181 & 14.888 & 24.761 & 29.195 & 35.340 \\
\hline Sudeste & 87.135 & 86.753 & 87.387 & 91.464 & 75.642 & 67.061 & 63.118 & 59.217 & 11.493 & 19.692 & 24.269 & 32.247 \\
\hline Sul & 46.210 & 47.615 & 51.473 & 52.875 & 33.748 & 34.451 & 34.268 & 32.352 & 12.462 & 13.164 & 17.205 & 20.523 \\
\hline Norte & 29.783 & 29.923 & 28.215 & 30.467 & 23.963 & 23.143 & 18.646 & 18.626 & 5.820 & 6.780 & 9.569 & 11.841 \\
\hline $\begin{array}{l}\text { Centro- } \\
\text { Oeste }\end{array}$ & 28.741 & 31.401 & 29.949 & 30.837 & 23.776 & 23.578 & 20.392 & 18.897 & 4.965 & 7.823 & 9.557 & 11.940 \\
\hline $\begin{array}{c}\text { Total } \\
\text { Brasil }\end{array}$ & 277.300 & 289.754 & 282.641 & 293.164 & 227.672 & 217.534 & 192.846 & 181.273 & 49.628 & 72.220 & 89.795 & 111.891 \\
\hline
\end{tabular}

Fonte: Elaborado pelos autores deste artigo com base em Instituto Nacional de Estudos e Pesquisas Educacionais Anísio Teixeira (2018).

Ao observar os percentuais de ingresso por modalidade, percebeu-se que em todas as regiões houve um decréscimo no número de ingressantes por ampla concor- rência; em contrapartida, verificou-se um incremento no número de estudantes que acessaram as IFES por meio de reserva de vagas (Figura 2). 
Figura 2 - Evolução do percentual de matrículas nas IFES de diferentes regiões, considerando ingresso em vagas novas por meio do Programa de Reserva de Vagas entre 2013 e 2016

\begin{tabular}{l}
$\begin{array}{c}\text { \% de ingresso } \\
\text { por Programa } \\
\text { de Reserva de } \\
\text { Vagas }\end{array}$ \\
\cline { 2 - 8 } \\
\cline { 2 - 8 }
\end{tabular}

Fonte: Elaborado pelos autores deste artigo com base em Instituto Nacional de Estudos e Pesquisas Educacionais Anísio Teixeira (2018).

A partir dos dados analisados pode-se inferir que houve um esforço institucional na direção do cumprimento da Lei $n^{0} \mathbf{1 2 . 7 1 1 / 2 0 1 2}$ nas IFES, no período entre 2013-2016, com incremento de 20,3 pontos percentuais de ingressantes nos cursos de graduação pelo Programa de Reserva de Vagas (PRV). Segundo o marco regulatório em tela, a sua implantação nas IFES poderia ocorrer de forma gradual, de modo que em 2013 estas teriam a obrigatoriedade de reservar, pelo menos, $12,5 \%$ do número de vagas ofertadas. Ainda recomendava que a implantação da modalidade de reserva de vagas seria progressiva, ao longo dos próximos quatro anos (2013-2016) até chegar à metade da oferta de vagas novas do ensino público superior federal. Considerando esta meta estabelecida pela Lei no seu artigo $8^{\circ}$, em 2016, as IFES deveriam oferecer $50 \%$ das vagas novas em PRV.

Ao avaliar os percentuais de acesso por meio do PRV nas regiões brasileiras, foram observados, para o ano de 2016, os seguintes percentuais (ver Figura 2): Nordeste $(40,4 \%)$; Norte $(38,9 \%)$; Sul $(38,8 \%)$; Centro-Oeste $(38,7 \%)$ e Sudeste $(35,3 \%)$, revelando um aumento progressivo desde 2013 em todas as regiões. As IFES localizadas no Nordeste do país foram as que promoveram os maiores percentuais de acesso via PRV; a região Sudeste, em contrapartida, foi a menos promoveu esse tipo de acesso.

A Figura 3 apresenta os percentuais-meta previstos pela Lei de Cotas e os percentuais observados de estudantes matriculados nas IFES no período de 2013 a 2016.

Figura 3 - Comparação entre os percentuais-meta previstos pela Lei de Cotas e os percentuais de ingresso por cotas nas IFES entre 2013 e 2016

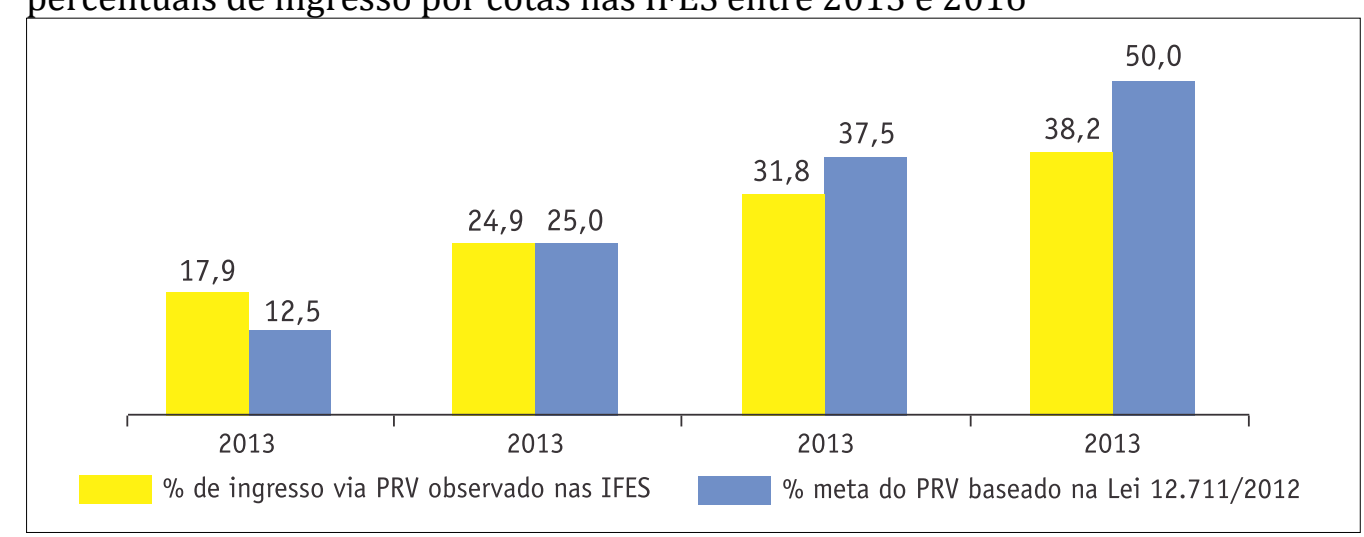

Fonte: Elaborado pelos autores deste artigo com base em Brasil (2012) e Instituto Nacional de Estudos e Pesquisas Educacionais Anísio Teixeira (2018). 
Após quatro anos de vigência da Lei $\mathrm{n}^{0}$ 12.711, o conjunto das IFES brasileiras atingiu o percentual de $38,2 \%$ de estudantes ingressantes por PRV. Os dados analisados revelaram que no ano de 2013 o percentual de ingresso nas IFES por cotas foi superior à meta prevista; no ano de 2014 este ingresso praticamente se igualou à meta. Nos anos seguintes os percentuais de ingresso observados estiveram abaixo da meta prevista em Lei. Estudo amostral, realizado pela Associação Nacional dos Dirigentes das Instituições Federais de Ensino Superior (2019), corrobora o resultado aqui apresentado a partir da análise dos dados censitários. No ano de 2018, o conjunto de IFES brasileiras ainda não havia conseguido atingir a meta prevista na Lei de Cotas, qual seja, 50\% dos ingressantes via PRV.

Considerando tais resultados, pode-se afirmar que o processo de inclusão social e étnico-racial nestas instituições foi impulsionado.
Contudo, é prudente destacar que existem questionamentos importantes acerca da real capacidade deste marco regulatório em promover o acesso às IFES de forma isonômica e justa, sobretudo se tomado como parâmetro o histórico de desigualdade étnica, racial e de classe no Brasil. Conforme Carvalho (2016), a Lei de Cotas, ao estabelecer a escola pública como seu foco primário, tratou da questão étnico-racial de forma unificada (pretos, pardos e indígenas = "PPI"), secundarizada e cindida por critérios de renda. Com isso, desconsiderou o efeito geral do racismo na massa estudantil brasileira na medida em que ele incide tanto nas escolas particulares quanto nas públicas, provocando desigualdades de acesso e de permanência entre os estudantes, em todos os níveis.

A Figura 4 apresenta o quantitativo de ingressantes nas IFES segundo diferentes critérios de inclusão.

Figura 4 - Evolução do quantitativo de estudantes ingressantes por PRV nas IFES, segundo diferentes critérios de inclusão previstos na Lei 12.711/2012, nos anos de 2013 a 2016

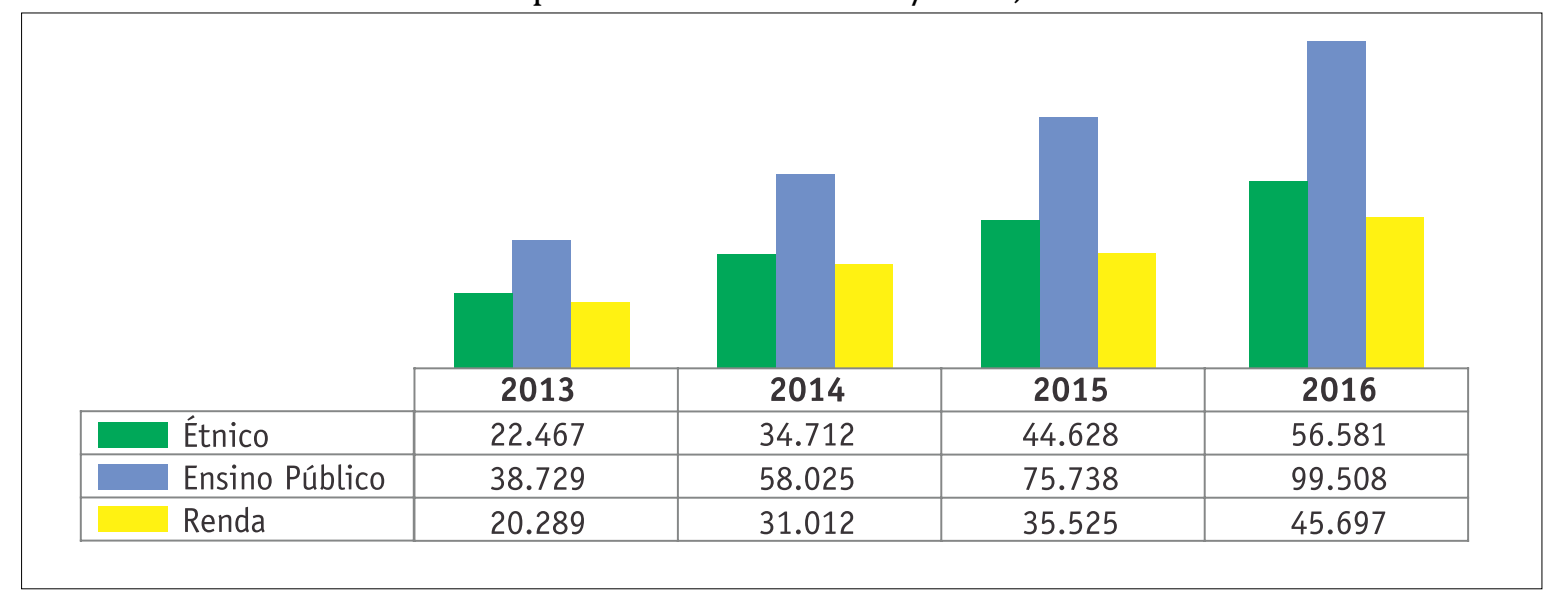

Fonte: Elaborado pelos autores deste artigo com base em Brasil (2012) e Instituto Nacional de Estudos e Pesquisas Educacionais Anísio Teixeira (2018).

No ano de 2016, dentre os critérios para acesso via PRV nas IFES registrados pelo Censo da Educação Superior, os mais frequentes foram: escola pública ( $n=99.508)$; étnico $(n=56.581)$ e renda familiar $(n=45.697)$. Embora o dado apresentado na Figura 4 não contemple a sobreposição das categorias de inclusão estabelecidas pela Lei de Cotas, ao se analisar o quantitativo de ingresso segundo diferentes critérios de inclusão, observou-se que, no período em análise, o critério de escola pública foi o que mais incluiu, sinalizando uma possível subsunção de uma sobre a outra. À luz dos argumentos de Carvalho (2016) poderse-ia questionar o potencial da Lei de Cotas em promover a inclusão de forma justa e isonômica. De acordo com este autor, a inclusão de pessoas por uma categoria ou outra, ou a subordinação de qualquer uma delas sobre as demais, não promoveria a justa inclusão, com o 
devido respeito à singularidade, às diferenças e os processos históricos específicos de emancipação dos grupos.

Outros autores argumentam que o recorte para escola pública privilegia grupos que, mesmo sem a lei, acessariam o ensino superior por terem cursado ensino médio em escolas públicas de excelência e, por conseguinte, estariam mais bem preparados e alcançariam melhores notas no Exame Nacional do Ensino Médio (Enem), saindo na frente no Sistema de Seleção Unificada (Sisu) adotado nas IFES. Por outro lado destacaram, também, a possibilidades de autodeclarações de renda e raça em desacordo com a autopercepção, forjando verdadeiros mecanismos de burla, ou seja, estratégias e táticas utilizadas por estudantes para se beneficiar da referida política de acesso (COUTRIM; PENA; SOUSA, 2018; MEDEIROS; MELLO NETO; GOMES, 2016).

Outra crítica se refere à tratativa da Lei no tocante à reserva de vagas aos povos indígenas. Baniwa (2013) e Carvalho (2016) chamam atenção para o fato de a Lei de Cotas fragilizar a representação política da luta dos indígenas por reconhecimento. Isto porque a luta pelos direitos indígenas no Brasil se estrutura a partir do direito coletivo, enquanto a Lei e o Sistema de seleção para ingresso nas IFES se dão de forma individualizada. Para o autor, "a individualização dos indígenas é um risco e uma ameaça aos princípios e modos próprios de vida indígena" (BA-
NIWA, 2013, p. 19). Além disso, a unificação do contingente étnico-racial (o PPI) colocou negros e indígenas, ambos, vítimas de discriminação na sociedade, a competirem entre si, com a provável desvantagem dos indígenas nesse confronto. Para Baniwa (2013) e Carvalho (2016), uma maior atenção ao quadro de exclusão étnico-racial poderia ter sido posta pelos que aprovaram a Lei de Cotas, seguindo os modelos das universidades federais que já haviam implementado ações afirmativas autonomamente até o ano de 2012, e que criaram cotas para indígenas separadas das cotas para negros.

Em relação ao turno de oferta dos cursos, em todos os horários de funcionamento houve aumento de ingresso pelo PRV nas IFES (Figura 5), tendo sido verificado os seguintes incrementos no período: integral $(27,6 \%)$; matutino $(23,1 \%)$; noturno $(23,1 \%)$ e vespertino $(18,4 \%)$. Este resultado chama atenção para o fato de que, se por um lado, tem-se aumentado o quantatitivo de ingressantes nas IFES com perfil de baixa renda (Figura 4), por outro, o maior incremento neste acesso foi observado para o turno integral, indicando a necessidade de uma política de assistência estudantil que ofereça condições materiais para a permanência do estudante. Em um contexto de contingenciamento de recursos na rede federal de ensino superior vivido pelo país, esta é uma questão preocupante que merece ser acompanhada em razão do risco de evasão deste grupo.

Figura 5 - Evolução do percentual de ingressantes via PRV nos cursos, considerando diferentes turnos, nos anos de 2013 a 2016

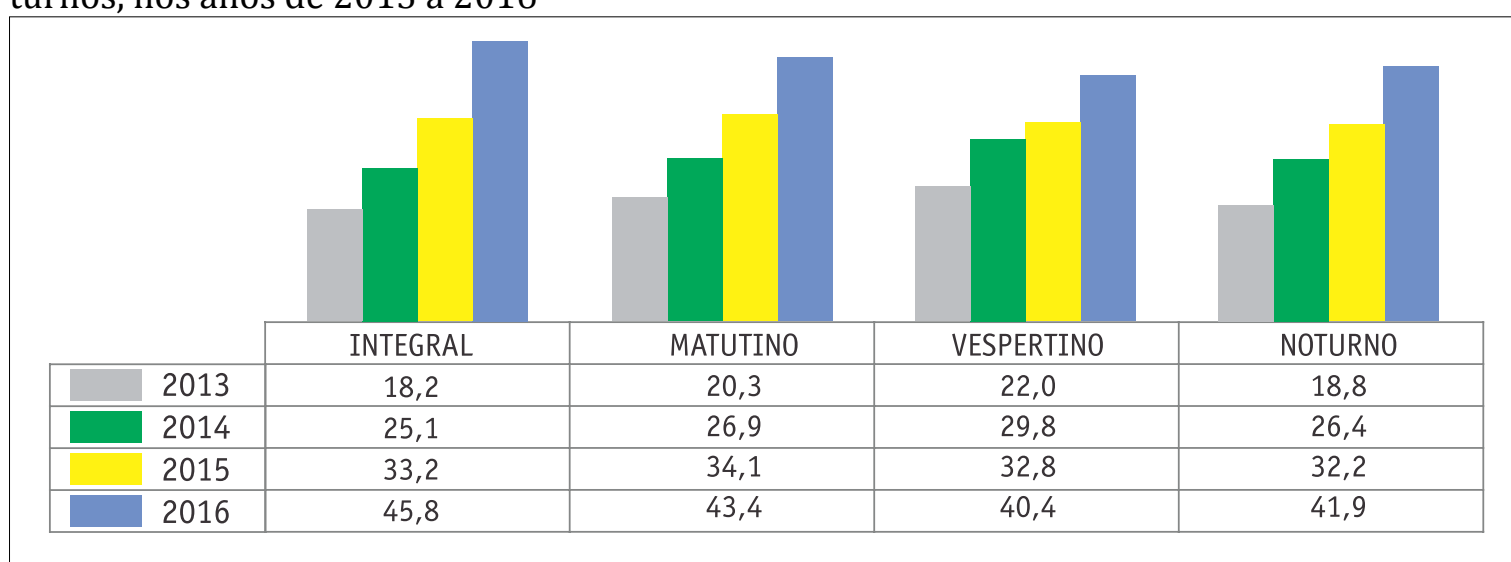

Fonte: Elaborado pelos autores deste artigo com base em Brasil (2012) e Instituto Nacional de Estudos e Pesquisas Educacionais Anísio Teixeira (2018). 
As condições de acesso e permanência dos estudantes em todos os níveis de ensino estão asseguradas na Constituição brasileira de 1988, na Lei de Diretrizes de Bases da Educação de 1996 e no Plano Nacional de Educação 2014-2024. O Plano REUNI, ao definir como algumas das suas diretrizes a ampliação das políticas de inclusão e assistência estudantil, alinhadas com os marcos legais descritos acima, comprometeu-se com a criação de uma política pública capaz de garantir a permanência dos estudantes nas IFES. Deste modo, no ano de 2010, foi criado o Programa Nacional de Assistência Estudantil (PNAES). Estudos realizados em universidades federais, nas quais o PNAES foi avaliado, revelaram a importância do Programa em contribuir com a permanência e a conclusão do curso de graduação de estudantes em situação de vulnerabilidade social (ALMEIDA, 2013; BARROS, 2014; TERRA, 2015; VARGAS, 2011).

Políticas públicas que tenham ênfase no acesso e na permanência material dos estudan- tes nos cursos de graduação são estruturantes e devem ser intensificadas. Contudo, para promover a efetiva igualdade de oportunidade de permanência e de sucesso educativo, faz-se necessário a articulação de um conjunto de ações que criem um ethos institucional caracterizado por um enfoque na permanência simbólica (SANTOS, 2017), que também envolve o enfretamento do racismo e da vulnerabilidade social (QUEIROZ; SANTOS, 2016), bem como a adoção da pedagogia da diversidade (SILVA, 2000), capaz de alavancar um giro decolonial na universidade (BALLESTRIN, 2013). Sem estas ações, todo o investimento jurídico e institucional corre o risco de promover não mais que processos de inclusão excludentes (AGUIAR et al, 2014; COSTA DE PAULA, 2017; NUNES; NEIRA, 2014).

Os resultados da análise da evolução do percentual de ingressantes via Programa de Reserva de Vagas (PRV) nas IFES, considerando as Grandes Áreas do Conhecimento da OCDE, estão sumarizados na Figura 6.

Figura 6 - Evolução do percentual de ingressantes via Programa de Reserva de Vagas (PRV) nas IFES, por Grandes Áreas do Conhecimento da OCDE nos anos de 2013 a 2016

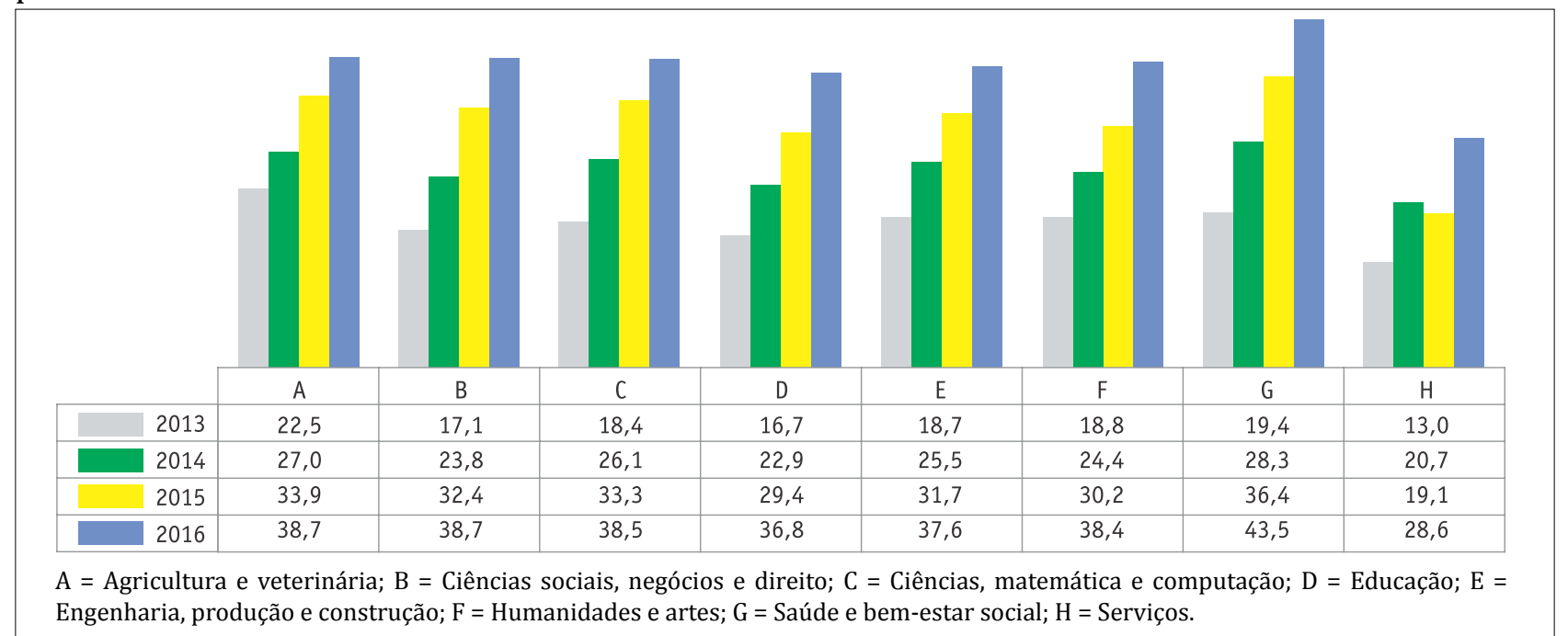

Fonte: Elaborado pelos autores deste artigo com base em Brasil (2012) e Instituto Nacional de Estudos e Pesquisas Educacionais Anísio Teixeira (2018).

Em todas as grandes áreas do conhecimento houve crescimento do número de ingressantes por PRV. No período avaliado, maiores incrementos em termos percentuais foram observados para as seguintes grandes áreas: $\mathrm{G}$ - Saúde e bem-estar social $(24,1 \%)$; B - Ciências so- ciais, negócios e direito (21,6\%); D - Ciências, matemática e computação $(20,1 \%)$ e E - Educação (20,1\%). Embora estes resultados não estejam desagregados por cursos específicos, permitindo uma análise aprofundada acerca da presença do público-alvo da Lei de Cotas 
em cursos de alta e baixa demanda, os dados indicam que, no momento em que se abriram as oportunidades com a Lei de Cotas, cresceu a ocupação de vagas por estudantes antes excluídos dos cursos das áreas de saúde, direito, negócios e computação. Assim, tais resultados poderiam sugerir uma possível tendência de dessegregação e de correção do histórico de desigualdades étnico-raciais nas profissões tidas como de maior prestígio social e remuneração.

Em estudo realizado em IFES localizadas no interior do Nordeste foi apresentado o perfil de egressos de cursos de diferentes áreas de conhecimento (ciências da saúde $=47,2 \%$; ciências agrárias, biológicas e ambientais $=17,8 \%$; ciências humanas = 19,5\%; educação / licenciaturas / formação de professores = 10,9\%; ciências exatas e tecnológicas $=4,6 \%$ ), revelando uma marcante presença de oriundos de escola pública e com baixa incorporação de capital cultural (incorporado, institucionalizado e objetivado), caracterizando origem social de camadas populares (SANTANA; MEIRELES; SÁ, 2017).

Queiroz e Santos (2016) investigaram o acesso a cursos de nível superior em uma IFES localizada na Bahia e identificaram que dentre os cursos de alta demanda oferecidos pela instituição, o curso de Psicologia foi o que atingiu a maior proporção de minorias sociais e raciais. Santos (2017), em estudo realizado em IFES no interior da Bahia, identificou presença marcante de estudantes autodeclarados negros (pretos = 22,5\%; pardos $=57,2 \%$ ) em cursos na área de saúde (Nutrição, Enfermagem, Psicologia, Medicina e Bacharelado Interdisciplinar em Saúde), referendando que há em curso no país um processo de mudança no perfil dos estudantes que ingressam nas universidades federais.

Outro estudo, realizado numa IFES localizada no interior da região Centro-Oeste, avaliou o perfil de ingresso em diferentes sistemas de acesso à universidade por processo de seleção universal e por cotas. Este estudo mostrou que ainda que o programa de reserva de vagas tenha impulsionado uma maior diversidade étnico-racial na instituição, esta mesma ten- dência não foi observada nos cursos de maior demanda/prestígio social, a exemplo dos cursos de Medicina e Direito (AGUIAR et al, 2014).

Em âmbito nacional, o estudo de Ristoff (2014) já apontava uma tendência de mudança do perfil social e racial em todos os cursos no campus universitário brasileiro, produto de programas de reserva de vagas em universidades públicas, mesmo antes da promulgação da Lei de Cotas. 0 referido autor ressalta, no entanto, que em cursos de alta demanda, tal mudança de perfil do estudante vinha ocorrendo de forma mais discreta.

\section{Considerações Finais}

Este estudo teve como objetivo principal avaliar como se deu a implementação da Lei $\mathrm{n}^{\mathrm{o}}$ 12.711/2012 no âmbito das IFES brasileiras. Buscou-se identificar até que ponto os campi tornaram-se mais diversos com o acesso de pessoas provenientes de escolas públicas, de famílias de baixa renda, bem com da população negra (preta e parda) e indígena.

Os dados levantados no presente artigo ratificaram que as IFES brasileiras foram impulsionadas pela Lei $\mathrm{n}$ - 12.711 a lidar com uma questão sociopolítica, ou seja, alterar a estrutura de ingresso nas instituições, com o intuito de estabelecer a preferência para determinado grupo e assim corrigir injustiças históricas. A partir dos resultados apresentados e discutidos ao longo do texto, pode-se afirmar que $o$ aparato administrativo das IFES logrou sucesso na aplicação da Lei de Cotas e, com isso, conseguiu promover uma mudança no perfil de ingressantes nas IFES, com consequente aumento da diversidade. Contudo, os resultados obtidos também sugerem indícios de que a opção adotada na Lei, de subordinar as categorias de inclusão (escola pública, renda, étnico-racial), pode contribuir com a geração de distorções no processo, de modo que o princípio fundamental das ações afirmativas seja desvirtuado, ou seja, com perda do espaço de centralidade. 
A retomada do foco das ações afirmativas para os grupos étnico-raciais é um desafio posto, dado que as IFES, desde a fundação dos cursos de formação profissional no período colonial, tem sido acessível somente para os herdeiros da aristocracia e funcionários da alta hierarquia, perfil este que vem se modificando gradativamente no país, embora ainda com discrepâncias regionais. Assim, é importante que estudos futuros monitorem, de maneira censitária, o perfil dos estudantes ingressantes nas IFES e avaliem se, efetivamente, a Lei de Cotas conseguiu promover a reparação histórica de exclusão de negros e indígenas do ensino superior brasileiro.

Não menos importante, dada a lacuna existente na produção científica brasileira, é o desenvolvimento de estudos que utilizem dados estruturados e longitudinais para avaliar a permanência dos estudantes no sistema de ensino superior. Estudos que relacionem o sucesso educativo com variáveis socioeconômicas e modalidade de ingresso nas instituições permitiriam, por exemplo, um mapeamento do sucesso daqueles que persistiram nas instituições e "cruzaram a linha de chegada", bem como dos obstáculos ou facilidades enfrentadas para concretizar tal objetivo.

Entende-se o Programa de Reserva de Vagas como parte de um conjunto de ações afirmativas necessárias no ensino superior. Os resultados apresentados e discutidos no presente estudo têm o potencial de promover o debate acerca dos relevantes benefícios inclusivos da Lei no 12.711/2012 nas IFES brasileiras. Entretanto, para radicalizar o processo de democratização e promoção efetiva da igualdade de oportunidades, este deve vir acompanhado de ações que garantam a permanência e a conclusão dos estudos com sucesso, uma vez que o acesso à universidade não garante, por si só, a permanência e a qualidade das aprendizagens que nela são realizadas.

Uma intervenção visando corrigir as distorções identificadas poderia ocorrer no momento de discussão da continuidade da Lei de Cotas, previsto para o ano de 2022. Em vez de basearse, novamente, em uma lógica monocausal e unidimensional e subsumir os princípios da desigualdade étnica e racial como secundários diante da precedência da escola pública, poder-se-ia construir sistemas de cotas independentes e articulados, baseados na teoria da complexidade, superpondo cotas étnicas, cotas raciais, cotas para escola pública e cotas para estudantes de baixa renda, cada uma delas com a porcentagem justa e factível, de modo que a sua superposição (inevitável, ainda que parcial) continuasse resultando na cifra final de $50 \%$ de cotas.

\section{REFERÊNCIAS}

AGUIAR, Márcio Mucedula. et al. Ação afirmativa e inclusão étnico-racial: estudo preliminar das políticas de acesso e permanência na Universidade Federal da Grande Dourados entre 2011 e 2013. O Social em Questão, v. 17, n. 32, p. 101-116, 2014. Disponível em: http://osocialemquestão.ser.puc-rio.br/media/ OSQ_32_5_Aguiar_Andrade_Marques_Almeida_WEB. pdf. Acesso em: 3 mar. 2016.

ALMEIDA, Jaqueline Cavalar Sales de. Avaliação da implantação do PNAES - Programa Nacional de Assistência Estudantil da UFPR: impacto e resultados para graduandos com fragilidade socioeconômica. 2013.156f. Dissertação (Mestrado Profissional em Gestão de Políticas Públicas) Universidade do Vale do Itajaí (Univali), Itajaí, SC, 2013. Disponível em: http://siaibib01.univali.br/ pdf/Jaqueline $\% 20$ Cavalari $\% 20$ Sales $\% 20$ de $\% 20$ Almeida.pdf. Acesso: 10 jun. 2018.

ASSOCIAÇÃO NACIONAL DOS DIRIGENTES DAS INSTITUIÇÕES FEDERAIS DE ENSINO SUPERIOR (ANDIFES). V Pesquisa do Perfil socioeconômico e cultural dos estudantes de graduação das universidades federais brasileiras. Brasília, DF: Fonaprace, 2019.

BALLESTRIN, Luciana. América Latina e o giro decolonial. Revista Brasileira de Ciência Política, Brasília, DF, n. 11, p. 89-117, maio/ago. 2013. Disponível em: http://www.scielo.br/pdf/rbcpol/ n11/04.pdf. Acesso em: 08 set. 2018.

BANIWA, G. A Lei das Cotas e os povos indígenas: mais um desafio para a diversidade. Cadernos do Pensamento Crítico Latino-Ameri- 
cano, n. 34, p. 18-21, jan. 2013. Disponível em: http://flacso.redelivre.org.br/files/2014/12/ XXXVcadernopensamentocritico.pdf. Acesso em: 8 set. 2018.

BARRos, Eliene Barreto de Araújo. Permanência dos estudantes de origem popular na Universidade: a bolsa moradia na UFBA. 2014. 127 f. Dissertação (Mestrado em Estudos Interdisciplinares sobre a Universidade) Instituto de Humanidades, Artes e Ciências Professor Milton Santos, Universidade Federal da Bahia (UFBA), Salvador, 2014. Disponível em: https://repositorio.ufba.br/ri/bitstream/ ri / 16542 / 1 / PER M AN \% C 3 \% 8 A N I A \% 20 DOS\%20ESTUDANTES\%20DE\%200RIGEM\%20 POPULAR\%20NA\%20UNIVERSIDADE-\%20\%20 A\%20BOLSA\%20MORADIA\%20NA\%20UFBA.pdf. Acesso: 10 jun. 2018.

BRASIL. Programa de Apoio a Planos de Reestruturação e Expansão das Universidades Federais: Reuni 2008 - Relatório do Primeiro Ano. Brasília, DF: MEC/SESu/DIFES, 2009. Disponível em: http://portal.mec.gov.br/index.php?option=com docman\&view=download\&alias $=2069$-reunirelatorio-pdf\&Itemid=30192. Acesso em: 28 ago. 2018.

BRASIL. Decreto no 6.096, de 24 de abril de 2007. Institui o Programa de Apoio a Planos de Reestruturação e Expansão das Universidades Federais - REUNI. Brasília, DF, 2007a. Disponível em: http://www.planalto.gov.br/ccivil_03/_ ato2007-2010/2007/decreto/d6096.htm. Acesso em: 28 ago. 2018.

BRASIL. Decreto no 6.094, de 24 de abril de 2007. Dispõe sobre a implementação do Plano de Metas Compromisso Todos pela Educação, pela União Federal, em regime de colaboração com Municípios, Distrito Federal e Estados, ea participação das famílias e da comunidade, mediante programas e ações de assistência técnica e financeira, visando a mobilização social pela melhoria da qualidade da educação básica. Brasília, DF, 2007b. Disponível em: http://www. planalto.gov.br/ccivil_03/_ato2007-2010/2007/ decreto/d6094.htm. Acesso em: 28 ago. 2018.

BRASIL. Lei no 12.711, de 29 de agosto de 2012. Dispõe sobre o ingresso nas universidades federais e nas instituições federais de ensino técnico de nível médio e dá outras providências. Brasília, DF, 2012. Disponível em: http://www.portal.mec.gov. br/cotas/docs/ lei_12711_2012.pdf. Acesso em: 28 ago. 2018.

BRASIL. Lei no 13.409, de 28 de dezembro de 2016. Altera a Lei no 12.711 , de 29 de agosto de 2012, para dispor sobre a reserva de vagas para pessoas com deficiência nos cursos técnico de nível médio e superior das instituições federais de ensino. Brasília, DF, 2016. Disponível em: http://www.planalto.gov. br/ccivil_03/_Ato2015-2018/2016/Lei/L13409. htm. Acesso em: 28 ago. 2018.

CARVALHO, José Jorge de. A política de cotas no ensino superior: ensaio descritivo e analítico do mapa de ações afirmativas no Brasil. Brasília, DF: Instituto de Inclusão no Ensino Superior e na Pesquisa, 2016.

COSTA DE PAULA, Maria de Fátima. Políticas de democratização da educação superior brasileira: limites e desafios para a próxima década. Avaliação, Campinas, SP, v. 22, n. 2, p. 301-315, jul. 2017. Disponível em: http://www.scielo.br/pdf/aval/ v22n2/1982-5765-aval-22-02-00301.pdf. Acesso em: 08 set. 2018.

COUTRIM, Rosa Maria da Exaltação; PENA, Mariza Aparecida Costa; SOUSA, Letícia Pereira de. Ação Afirmativa em foco: táticas e estratégias de candidatos para burlar a Lei de Cotas em uma universidade pública. Revista de Educação PUCCampinas, Campinas, SP, v. 23, n. 1, p. 142-154, 2018. Disponível em: http://periodicos.puccampinas.edu.br/seer/index.php/reveducacao/ article/view/3781. Acesso em: 08 set. 2018.

GABINETE DE ESTATÍSTICAS DA UNIÃO EUROPEIA (EUROSTAT); ORGANIZAÇÃO DAS NAÇÕES UNIDAS PARA A EDUCAÇÃO, A CIÊNCIA E A CULTURA (UNESCO); ORGANIZAÇÃO PARA A COOPERAÇÃO E DESENVOLVIMENTO ECONÔMICO (OCDE). Classificação internacional: área de formação e treinamento - manual de classificação. Brasília, DF: Instituto de Inclusão no Ensino Superior e na Pesquisa, 2000. Disponível em: http://download. inep.gov.br/download/superior/2009/Tabela OCDE_2009.pdf. Acesso em: 8 ago. 2018.

GUARNIERI, Fernanda Vieira; MELO-SILVA, Lucy Leal. Cotas universitárias no Brasil: análise de uma década de produção científica. Psicologia Escolar e Educacional, São Paulo, v. 21, n. 2, p. 183-193, maio/ago. 2017. Disponível em: http://www.scielo. br/pdf/pee/v21n2/2175-3539-pee-21-02-00183. pdf. Acesso em: 08 set. 2018.

HERINGER, Rosana; FERREIRA, Renato. Análise das principais políticas de inclusão de estudantes negros no ensino superior no Brasil no período 2001-2008. In: PAULA, Marilene de; HERINGER, Rosana (org.). Caminhos convergentes: Estado e sociedade na superação das desigualdades raciais 
no Brasil. Rio de Janeiro: Heinrich Böll Stiftung, 2009. p. 137-196.

INSTITUTO NACIONAL DE ESTUDOS E PESQUISAS EDUCACIONAIS ANÍSIO TEIXEIRA (INEP). Dados. Microdados. Censo da Educação Superior - 20132016. Disponível em: http://portal.inep.gov.br/ microdados. Acesso em: 08 set. 2018.

INSTITUTO NACIONAL DE ESTUDOS E PESQUISAS EDUCACIONAIS ANÍSIO TEIXEIRA (INEP). Censo da Educação Superior: sinopse estatística 2005. Brasília, DF, 2007. Disponível em: http://inep.gov. $\mathrm{br} / \mathrm{web} /$ guest/sinopses-estatisticas-da-educacaosuperior. Acesso em: 28 ago. 2018.

INSTITUTO NACIONAL DE ESTUDOS E PESQUISAS EDUCACIONAIS ANÍSIO TEIXEIRA (INEP). Censo da Educação Superior 2016: notas estatísticas. Brasília, DF, 2017. Disponível em: http://download. inep.gov.br/educacao_superior/censo_superior/ documentos/2016/notas_sobre_o_censo_da_ educacao_superior_2016.pdf. Acesso em: 28 ago. 2018.

MEDEIROS, Hugo Augusto Vasconcelos; MELLO NETO, Ruy de Deus; 08 set. 2018.GOMES, Alfredo Macedo. Limites da lei de cotas nas universidades públicas federais. Arquivos Analíticos de Políticas Educativas, v. 24, n. 6, p. 2-20, jan. 2016. Disponível em: https://www.researchgate.net/ publication/291812650_Limites_da_lei_de_cotas_ nas_universidades_publicas_federais. Acesso em: 08 set. 2018.

MINISTÉRIO DA EDUCAÇÃO (MEC). Ensino Superior. Entenda as cotas para quem estudou todo o ensino médio em escolas públicas. Brasília, DF, 2012. Disponível em: http://portal.mec.gov.br/cotas/ sobre-sistema.html. Acesso em: 08 set. 2018.

NUNES, Mário Luiz Ferrari; NEIRA, Marcos Garcia. Processos de inclusão excludente presentes no ensino superior privado. Educação \& Realidade, Porto Alegre, v. 39, n. 4, p. 1209-1228, out./dez. 2014. Disponível em: http://www.scielo.br/pdf/ edreal/v39n4/14.pdf. Acesso em: 08 set. 2018.

QUEIROZ, Delcele Mascarenhas; SANTOS, Carlinda Moreira. As mulheres negras brasileiras e o acesso à educação superior. Revista da FAEEBA - Educação e Contemporaneidade, Salvador, v. 25, n. 45, p. 71-87, jan./abr. 2016. Disponível em: https:// www.revistas.uneb.br/index.php/faeeba/article/ view/2286/1592. Acesso em: 08 set. 2018.

RISTOFF, Dilvo. 0 novo perfil do campus brasileiro: uma análise do perfil socioeconômico do estudante de graduação. Avaliação, Campinas, SP, v. 19, n. 23, p. 723-747, nov. 2014. Disponível em: http://www. scielo.br/pdf/aval/v19n3/10.pdf. Acesso em: 08 set. 2018.

SANTANA, Luciana Alaíde Alves; MEIRELES, Everson; SÁ, Virgínio Isidro Martins de. Os não herdeiros: egressos de cursos de graduação em uma universidade do interior do Nordeste. Gueto, Cruz das Almas, BA, v. 9, p. 108-130, 2017.

SANTOS, Adilson Pereira dos. P. Itinerário das ações afirmativas no ensino superior público brasileiro: dos ecos de Durban à Lei das Cotas. Revista de Ciências Humanas, Viçosa, MG, v. 12, n. 2, p. 289317, jul./dez. 2012. Disponível em: http://flacso. redelivre.org.br/files/2014/05/1132.pdf. Acesso em: 8 ago. 2018.

SANTOS, Dyane Brito Reis. Curso de branco: uma abordagem sobre o acesso e permanência de estudantes de origem popular nos cursos da saúde da Universidade Federal do Recôncavo da Bahia (UFRB). Revista Contemporânea de Educação, v. 12, n. 23, p. 31-50, jan./abr. 2017.

SILVA, Tomaz Tadeu da. A produção social da identidade e da diferença. In. SILVA, Tomaz Tadeu da (org.). Identidade e diferença. Rio de Janeiro: Vozes, 2000. p. 73-102.

TERRA, Vitor Fernando. Implementação da política de assistência estudantil: um estudo de três instituições federais de ensino superior localizadas no Sul de Minas Gerais. 2015. 203 f. Dissertação (Mestrado Profissional em Administração Pública) - Universidade Federal de Lavras (UFLA), Lavras, MG, 2015. Disponível em: http://repositorio.ufla. br/jspui/bitstream/1/9341/2/DISSERTACAO_ Implementa \% c 3\%a 7\% c 3\%a 3 o \% 20 da $\% 20$ pol\%c3\%adtica\%20de\%20assist\%c3\%aancia\%20 estudantil.pdf. Acesso em: 10 jun. 2018.

VARGAS, Michely de Lima Ferreira. Ensino superior, assistência estudantil e mercado de trabalho: um estudo com egressos da UFMG. Avaliação, Campinas/Sorocaba, SP, v. 16, n. 1, p. 149-163, mar. 2011. Disponível em: http://www.scielo. br/scielo.php?script=sci_arttext\&pid=S141440772011000100008\&lng=en\&nrm=iso. Acesso em: 07 ago. 2019.

Recebido em: 24/03/2019 Aprovado em: 09/08/2019

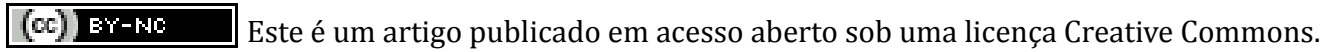

